\title{
Implications of Anti-AAPI Racism in Light of the COVID-19 Pandemic
}

DON HOANG (1)

SAVREEN SARAN (1)

MELODY WANG (D)

ASHLEY WONG (D)

MARIAM SHALABY (D)

*Author affiliations can be found in the back matter of this article

\section{ABSTRACT}

Xenophobia against Asian American and Pacific Islander (AAPI) communities has spanned decades of American history, recently escalating in the context of the COVID-19 pandemic. According to the Asian Pacific Policy and Planning Council, there were 2583 reports of anti-Asian hate incidents as of August 2020, with reports only rising [1]. The federal government has done little to ameliorate this racial discrimination. Although $\mathrm{H}$. Res 908, condemning all forms of anti-Asian sentiment, passed in September, 2020, the resolution took over 6 months to pass with 164 members of the House voting against the resolution. The national response to AAPI xenophobia parallels the experiences of the AAPI community within medicine, promoting a cycle of mental health issues stemming from prejudice and lack of systemic support.

In particular, AAPI students in the medical field face the same encounters of discrimination in addition to the stress and pressure associated with medical school. Students witness encounters of xenophobia within their future career paths, instigating a sense of fear and uncertainty of how they will be perceived by future patients [2]. Concerns of xenophobia are compounded by the model minority myth, which implicates that academic achievement and accomplishments define self-worth, value, and identity [3]. A profound repercussion is that this leads to an unwillingness to seek out help and address mental health concerns within the AAPI community.

Ultimately, there lies a challenge as to how we can adequately support our current AAPI medical community. Firstly, an increase in mental health support for AAPI students is pertinent, as this increase may incentivize students to seek help. Secondly, medical education requires more topics regarding diversity, which aid in dismantling the model minority myth while teaching faculty about the presence and history of
CORRESPONDING AUTHOR:

\section{Don Hoang}

Penn State College of

Medicine, US

dhoang@pennstatehealth. psu.edu

\section{KEYWORDS:}

Asian American; Pacific Islander; AAPI; Mental Health; COVID-19; Pandemic; Xenophobia; Medical Students; Medical Education; Racism; Model Minority; Discrimination; Academic Medicine

TO CITE THIS ARTICLE: Hoang D, Saran S, Wang M, Wong A, Shalaby M. Implications of Anti-AAPI Racism in Light of the COVID-19 Pandemic. ISMMS Journal of Science and Medicine. 2021; 1(1): 15, pp. 1-2. DOI: https://doi. org/10.29024/ijsm.41 
xenophobia. Lastly, systemic lack of representation necessitates an institutional push for more Asian-American representation in academia. Despite Asians being over-represented in medical recruitment, AAMC reports that only $6 \%$ of Asians are professors, 3.52\% are chairpersons, and $0 \%$ are deans [4]. The COVID-19 pandemic has illustrated how pervasive AAPI xenophobia is both within and beyond the medical institution; therefore, we have the responsibility to mitigate this dilemma.

\section{COMPETING INTERESTS}

The authors have no competing interests to declare.

\section{AUTHOR AFFILIATION}

Don Hoang (D) orcid.org/0000-0002-7172-8176

Penn State College of Medicine, US

Savreen Saran (D) orcid.org/0000-0003-2418-1582

Penn State College of Medicine, US

Melody Wang (iD) orcid.org/0000-0002-7399-4654

Penn State College of Medicine, US

Ashley Wong (D) orcid.org/0000-0003-3568-111X

Penn State College of Medicine, US

Mariam Shalaby (D) orcid.org/0000-0001-6719-408X

Penn State College of Medicine, US

\section{REFERENCES}

1. Stop AAPI Hate National Report: 3.19.20 - 8.5.20. (2020, August 27). Asian Pacific Policy \& Planning Council. Retrieved October 7, 2020, from http://www.asianpacificpolicyandplanningcouncil.org/ wp-content/uploads/STOP_AAPI_Hate_National_Report_3.19-8.5.2020.pdf.

2 Jan, T. (2020, May 19). Asian American doctors and nurses are fighting racism and the coronavirus. The Washington Post. https://www.washingtonpost.com/business/2020/05/19/asian-americandiscrimination/.

3. Fuchs, C. (2017, August 22). Behind the 'Model Minority' Myth: Why the 'Studious Asian' Stereotype Hurts. NBC News. https://www.nbcnews.com/news/asian-america/behind-model-minority-myth-whystudious-asian-stereotype-hurts-n792926.

4 Lu, F., Yee, L. L., An, C., \& Zhang, L. (2016, January 19). Increasing Asian Inclusion in Academic Medicine and Leadership [Webinar]. Association of American Medical Colleges. https://www.aamc.org/ what-we-do/diversity-inclusion/learning/webinar-asian-inclusion.

TO CITE THIS ARTICLE: Hoang D, Saran S, Wang M, Wong A, Shalaby M. Implications of Anti-AAPI Racism in Light of the COVID-19 Pandemic. ISMMS Journal of Science and Medicine. 2021; 1(1): 15, pp. 1-2. DOI: https://doi. org/10.29024/ijsm.41

Submitted: 28 December 2020 Accepted: 28 December 2020

Published: 27 January 2021

\section{COPYRIGHT:}

(c) 2021 The Author(s). This is an open-access article distributed under the terms of the Creative Commons Attribution 4.0 International License (CC-BY 4.0), which permits unrestricted use, distribution, and reproduction in any medium, provided the original author and source are credited. See http://creativecommons.org/ licenses/by/4.0/.

ISMMS Journal of Science and Medicine is a peer-reviewed open access journal published by Levy Library Press. 